\title{
FURTHER SHOCK-TUBE STUDIES BY INFRARED EMISSION OF THE DECOMPOSITION OF AMMONIA
}

\author{
BY T. A. JACOBS ${ }^{1}$ \\ California Institute of Technology, Pasadena, California \\ Received September 12, 1962
}

\begin{abstract}
The decomposition of shock heated $\mathrm{NH}_{3}$ has been studied by monitoring the infrared emission of the $2.7-3.2 \mu$ fundamental region. It appears that the decomposition follows a kinetic law given by $\mathrm{d}\left(\mathrm{NH}_{3}\right) / \mathrm{d} t=k\left(\mathrm{NH}_{3}\right)^{3 / 2}$. $(\mathrm{Ar})^{1 / 2}$, with $k=\left(2.5 \times 10^{13}\right) e^{-77,700 / R T} 1 . /$ mole-sec.
\end{abstract}

\section{Introduction}

Some time ago this Laboratory initiated a program to study decomposition kinetics in a shock tube employing infrared emission techniques. The choice to make shock tube measurements in the infrared region of the spectrum was made possible by the appearance on the commercial market of infrared detectors of rapid response (time constants $<1 \mu \mathrm{sec}$.). Although Windsor, Davidson, and Taylor ${ }^{2}$ preceded us in their study of CO vibrational relaxation in a shock tube, we believe this Laboratory was the first to report kinetic rate data obtained from infrared emission.

In previous publications, ${ }^{3}$ we reported on our preliminary study of the homogeneous rate of decomposition of $\mathrm{NH}_{3}$ in a shock tube. We have subsequently improved our experimental procedures and in this paper we present the results of a new series of measurements which we believe gives more insight into the nature of the $\mathrm{NH}_{3}$ decomposition processes.

Our basic technique of measurement remained as before, i.e., the infrared emission intensity of the $3 \mu$ band of $\mathrm{NH}_{3}$ was recorded as a function of time. For judiciously chosen optical depths, the gas may be shown to be transparent, to a reasonable approximation, so that the emission intensity is proportional to the $\mathrm{NH}_{3}$ concentration. We abandoned, however, our earlier attempts to measure initial reaction rates by extrapolation to zero time. Instead we measured the $\mathrm{NH}_{3}$ concentration for a period of time behind the shock wave and then, by using the conventional integration methods, determined an apparent order of reaction. The difference in these measuring techniques may be inferred by reference to Fig. 1 which is reproduced from an actual experimental record. From the figure it can be seen that, due to the response time of the detector and associated electronics, linear extrapolation of the trace is likely to yield a considerable error in the initial slope; however, only a relatively small error is expected

(1) Aerospace Corp., El Segundo, California

(2) M. Windsor, N. Davidson, and R. Taylor, "Seventh Symposium on Combustion," Butterworths Scientific Publications, London, 1959.

(3) (a) T. A. Jacobs, Calif. Inst. of Tech. Technical Note 12, AF 18(603)-2 (1960); (b) Ph.D. Thesis, Calif. Inst. of Tech., 1960; (c) "Eighth Symposium on Combustion," Butterworths Scientific Publications, London, 1962. in the initial trace height. Therefore, we have used linear extrapolation to determine only the proportionality constant relating oscilloscope voltage to $\mathrm{NH}_{3}$ concentration (since the gas composition is known immediately behind the shock wave). Data then were taken from the trace only for times greater than those indicated by point $\mathrm{A}$ in Fig. 1. Radiation of reaction intermediates in the wave length region of measurement was assumed to be negligible.

\section{Experimental Studies}

A. The Shock Tube and Associated Measuring Equipment.The shock tube and associated equipment are of conventional design and remain essentially as described earlier. ${ }^{3}$ Improvements incorporated in the gas handling and pumping systems have reduced the ultimate pressure achieved in the tube from 0.1 to $0.05 \mu$. The leak rate has been reduced from 0.1 to about 0.02 $\mu / \min$.

Radiant emission from the shock tube passed through sapphire observation windows and was focused in the slits of a monochromater by means of a $\mathrm{LiF}$ lens. $\mathrm{A} \mathrm{NaCl}$ prism allowed a spectral bandpass of 2.7 to $3.2 \mu$ to be covered with about $1 \mathrm{~mm}$. of slit width.

Detection was provided by a Westinghouse Type 812 golddoped germanium cell. Using a carefully constructed cathode follower and a cell load resistance of $10^{5} \mathrm{ohms}$, the measured time constant of the detector was found to be approximately 0.7 $\mu$ sec. The output of the dectector was fed to a Tektronix Type 535 oscilloscope. Shock velocity measurements were made using thin film resistance gages and a Berkeley counter.

B. Test Gas Mixtures.-Test gas mixtures of 1 and $8 \%$ (nominal) $\mathrm{NH}_{3}$ in Ar at a total pressure of 1000 p.s.i. were prepared by the Matheson Company. Chemical analysis provided by Matheson gave the $\mathrm{NH}_{3}$ concentration with an accuracy of about $1 \%$. In our previous studies, we prepared our mixtures of $\mathrm{NH}_{3}$ and $\mathrm{Ar}$ in a low-pressure mixing system with the total gas pressure never exceeding 15 p.s.i.; a chemical analysis ( $3 \%$ precision) of the gas introduced into the tube was performed for each shock tube run to determine the gas composition.

Unfortunately, our chemical analysis was designed to measure the fraction of $\mathrm{NH}_{3}$ in $\mathrm{Ar}$ only, rather than to determine the total composition including impurities. As we shall discuss later, we now suspect that the $\mathrm{NH}_{3}$ in our original study was contaminated with oxygen.

C. Calculation of Thermodynamic Properties behind the Shock. - The labor of calculating the thermodynamic parameters after passage of a shock wave in a non-dilute gas mixture was greatly reduced in the present investigation by the use of a digital computer program. We are indebted to Dr. James Lloyed of the California Institute of Technology for this program and 


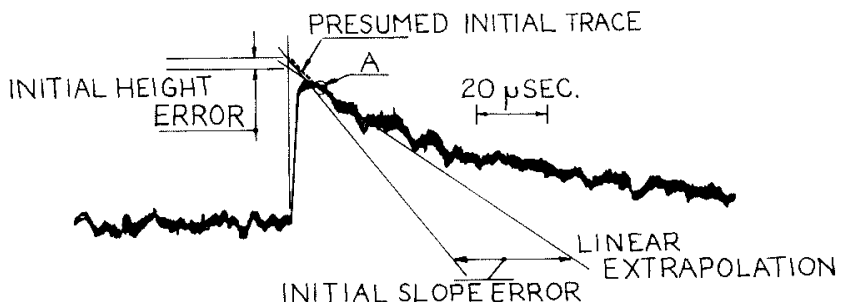

Fig. 1.-Typical experimental record, with indication of errors incurred in extrapolation of experimental trace to the initial time of reaction: $T=2480^{\circ} \mathrm{K} ., P=1.21 \mathrm{~atm}$., $7.9 \% \mathrm{NH}_{3}$, balance Ar. we then determined an apparent reaction order that yielded the best fit to the concentration-time records. Running the gamut of integral and half integral orders, we found that the $3 / 2$ order with respect to $\mathrm{NH}_{3}$ yielded the best fit for all our experimental data. Four records, shown in Fig. 2, indicate the closeness of the $3 / 2$ order fit. Thus, in determining rate constants, $3 / 2$ order in $\mathrm{NH}_{3}$ was assumed; least square straight line correlation then yielded the rate constant $k^{\prime}$ from the integrated form of the rate equation

$$
\left[\frac{\left(\mathrm{NH}_{3}\right)_{0}}{\left(\mathrm{NH}_{3}\right)}\right]^{1 / 2}=1+1 / 2 k^{\prime}\left(\mathrm{NH}_{3}\right)_{0}{ }^{1 / 2} t
$$

where $t$ is the particle time, obtained from oscilloscope time by

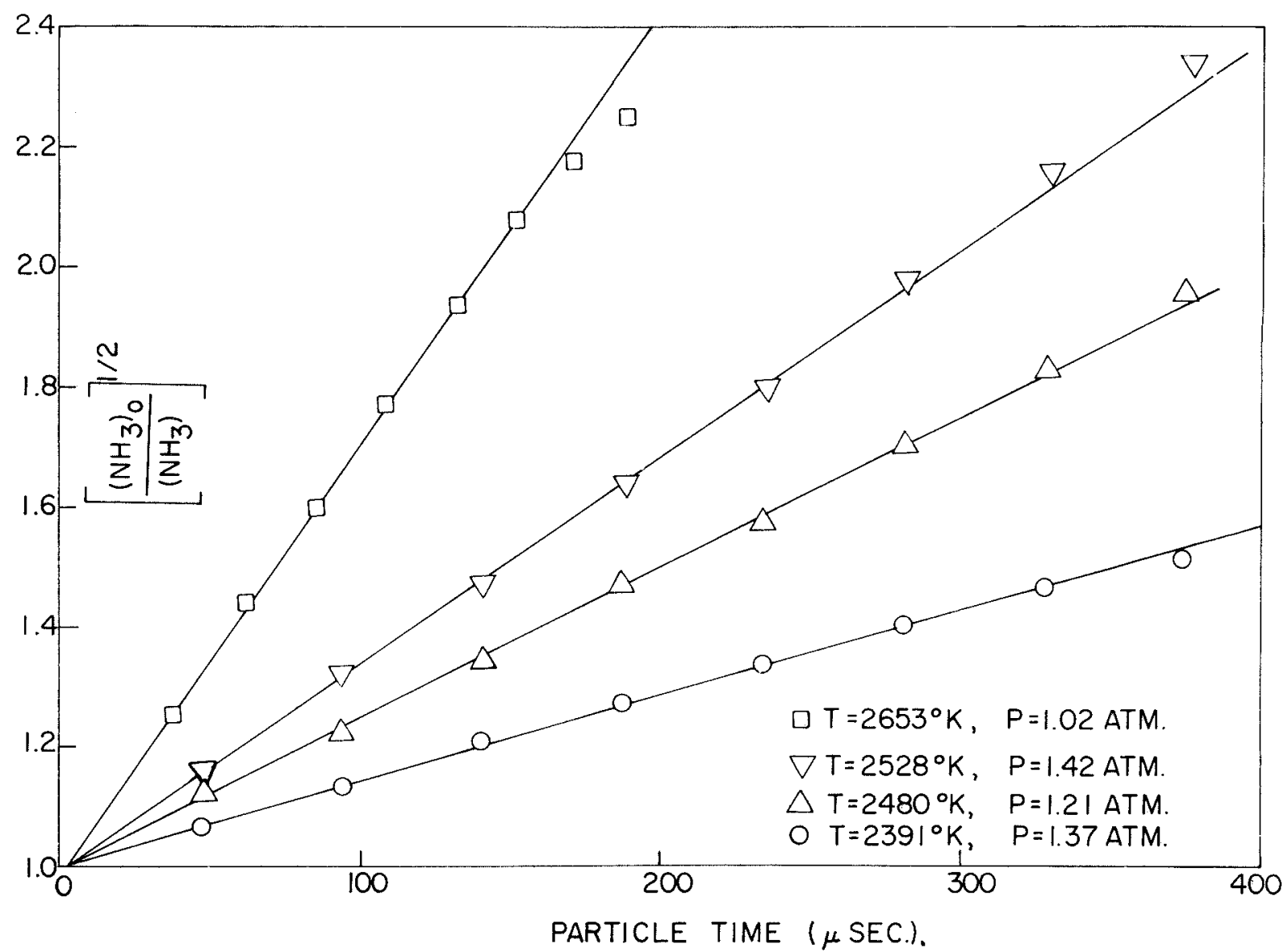

Fig. 2. - Reduction of four experimental records assuming $\mathrm{d}\left(\mathrm{NH}_{3}\right) / \mathrm{d} t \propto\left(\mathrm{NH}_{3}\right)^{3 / 2}$.

to the Western Data Processing Center, U.C.L.A., for the use of an IBM 709 computer.

D. Experimental Results.--.-The rate of decomposition of $\mathrm{NH}_{3}$ in Ar has been measured between 2000 and $3000^{\circ} \mathrm{K}$. by following the rate of decrease of $\mathrm{NH}_{3}$ emission intensity in the 2.7 to $3.2 \mu$ wave length region. Figure 1 illustrates a typical experimental record.

Assuming transparent gas radiation, the oscillocope voltage, $V$, registered by the detector is direetly proportional to the ammonia concentration. Thus

$$
\frac{V}{V_{0}}=\frac{\left(\mathrm{NH}_{3}\right)}{\left(\mathrm{NH}_{3}\right)_{0}}
$$

where the subscript 0 refers to conditions immediately behind the shock wave.

By using eq. 1 and the calculated thermodynamic parameters, each experimental record yielded $\left(\mathrm{NH}_{3}\right)$ as a function of time at a particular temperature. We took the temperature to be the temperature of the gas immediately after passage of the shock wave. Because the heat of formation of $\mathrm{NH}_{3}$ is $-11.04 \mathrm{kcal}$., the calculated difference in the frozen and equilibrium temperatures behind the shock wave is only about $150^{\circ}$ for an $8 \%$ mixture of $\mathrm{NH}_{3}$ in Ar. We determined, however, that this temperature decrease was largely compensated for by shock wave attenuation in our tube. Using conventional integral methods, use of the appropriate density ratio. In eq. 2 , the rate constant includes the (Ar) dependence. It should be noted from the figure that the extrapolation to zero time did not quite yield the correct initial concentration.

We are unable to determine unequivocally the Ar reaction order by changing concentration because of limitations of detector sensitivity, gas transparency requirements, and shock testing time, which restricted us to a narrow range of encentrations. However, by taking

$$
k^{\prime}=(\operatorname{Ar})^{n} k
$$

the least scatter of the data points on an Arrhenius type plot of rate constant $v s$. reciprocal temperature was obtained for $n=$ 1/2. Figure 3 shows the Arrhenius plot. The apparent activation energy determined on this basis was found to be $77.7 \mathrm{kcal} . /$ mole, with a pre-exponential factor of $2.5 \times 10^{13} \mathrm{l} . / \mathrm{mole}$-sec.

\section{Conclusion}

Our investigation supports the tentative conclusion that the thermal decomposition of ammonia follows a kinetic law given by

$$
\frac{\mathrm{d}\left(\mathrm{NH}_{3}\right)}{\mathrm{d} t}=l\left(\mathrm{NH}_{3}\right)^{3 / 2}(\mathrm{Ar})^{1 / \mathrm{s}}
$$

with $k=\left(2.5 \times 10^{13}\right) e^{-77.700 / R^{T}} 1 . /$ mole-sec 
Mathews, Gibbs, and Holsen 4 in a recent report have studied the $\mathrm{NH}_{3}$ decomposition using a single pulse shock tube. They determined an activation energy of about $80 \mathrm{kcal}$./mole based on unimolecular decomposition. Since the activation energy would not be very sensitive to the assumed order of reaction, it appears that our experimental data are in agreement with the results obtained in ref. 4.

In our earlier work we reported an activation energy of about $52 \mathrm{kcal}$. for the homogeneous $\mathrm{NH}_{3}$ decomposition. The scant data available in the literature, however, indicated that a value in the neighborhood of $80 \mathrm{kcal}$. would be more likely. Hinshelwood and Burk's study of the homogeneous decomposition ${ }^{5}$ yielded the qualitative facts that the decomposition could not be detected below temperatures of about $1500^{\circ} \mathrm{K}$., whereas above this temperature it was too fast to be measured with the equipment available to them at the time. (More recently, Sage, using a ballistic piston, found similarly that there was practically no conversion of $\mathrm{NH}_{3}$ below $1500^{\circ} .^{6}$ ) Hinshelwood inferred from his study that an activation energy of at least $80 \mathrm{kcal}$. was called for in order to explain the observations. ${ }^{7}$ If we couple this estimate with the reported activation energies ${ }^{8}$ of $45-49.5 \mathrm{kcal}$. for the oxidation of $\mathrm{NH}_{3}$, the low value of activation energy obtained in our original measurements certainly suggests oxygen contamination. One would, of course, suspect air leakage, since the manufacturers' minimum purity specifications (anhydrous grade $\mathrm{NH}_{3}, 99.99 \%$; standard grade $\mathrm{Ar}, 99.998 \%$ ) indicate negligible contaminants. We therefore set about to improve our vacuum system as was discussed earlier. Also, as discussed before, we replaced the low pressure mixing system with high pressure premixed gases, prepared by the Matheson Co.

It recently has come to our attention that many liquefied gases purchased on the West Coast of the United States are shipped via tank cars with small

(4) J. C. Mathews, M. E. Gibbs, and J. N. Holsen, "A Shook Tube Study of the Ammonia Decomposition Reaction," presented at the 139 th National Meeting, American Chemical Society, St. Louis, Mo. 1961.

(5) C. N. Hinshelwood and R. T. Burk, J. Chem. Soc. (London), 127, $1105(1925)$.

(6) B. H. Sage, private communication.

(7) C. N. Hinshelwood, "The Kineties of Chemical Change," Oxford Univ. Press, London, 1940.

(8) E. R. Stephens and R. N. Pease, J. Am. Chem. Soc.. 72, 1188 (1950); 74, 3480 (1952); J. Verwimp and A. van Tiggelen, Bull. soc. chim. Belges, 62, $205(1953)$.

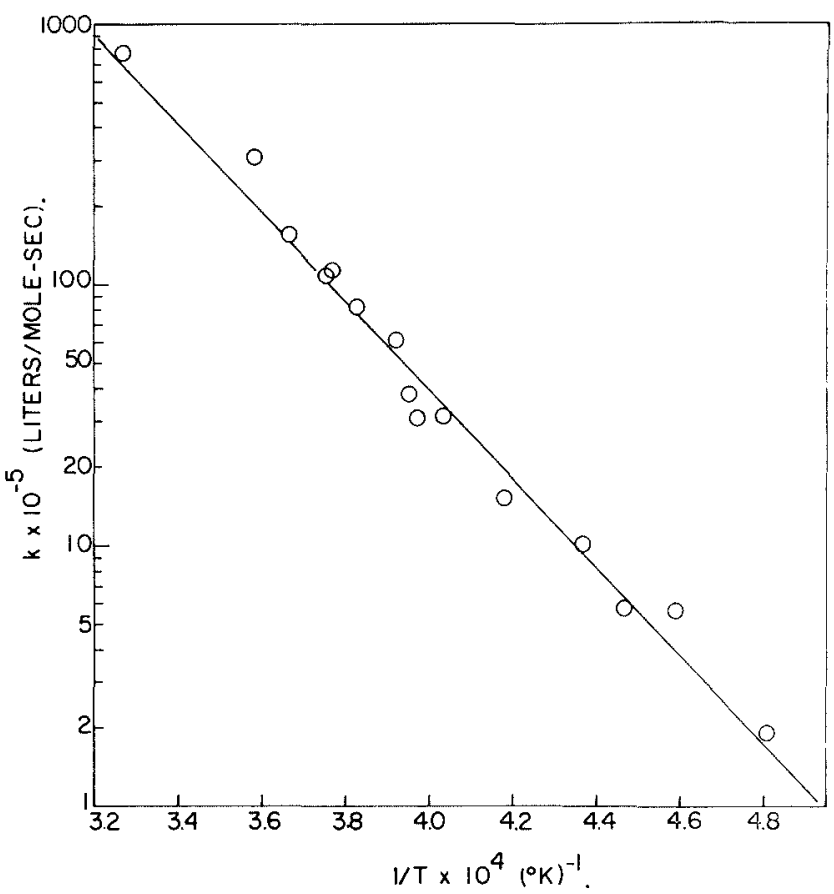

Fig. 3.-Determination of apparent activation energy assuming that $\mathrm{d}\left(\mathrm{NH}_{3}\right) / \mathrm{d} t=k\left(\mathrm{NH}_{3}\right)^{3 / 2}(\mathrm{Ar})^{1 / 2}$.

cylinders being filled at railroad sites. Only minimum precautions are taken (from a laboratory, not commercial, viewpoint) to remove entrapped air in the cylinders. Apparently, the cylinders are not pumped before filling; rather, the liquefied gas itself is used to expel air. The premixed gases used in the present study were prepared by Matheson at their East Rutherford plant and were not subject to this air contamination. We believe that objectionable contamination has been eliminated in our present experiments and the data obtained are representative of the homogeneous thermal decomposition of $\mathrm{NH}_{3}$.

The suggestion of a mechanism for the decomposition presents a problem which we prefer to defer until f urther experimental study is accomplished.

Acknowledgment.-The author wishes to thank Professor S. S. Penner for his stimulating interest during the course of this work. This work was supported by the Air Force Office of Scientific Research under Contract AF 49(638)-984. 